\title{
Measurement of Regional Neuronal Removal of Norepinephrine in Man
}

\author{
David S. Goldstein, Reuven Zimlichman; Robin Stull, Joan Folio, Paul D. Levinson, and Harry R. Keiser \\ Hypertension-Endocrine Branch, National Heart, Lung, and Blood Institute, National Institutes of Health, Bethesda, Maryland 20205 \\ Irwin J. Kopin \\ Division of Intramural Research, National Institute of Neurological and Communicative Disorders and Stroke, \\ National Institutes of Health, Bethesda, Maryland 20205
}

\begin{abstract}
We describe here and validate an in vivo technique to measure the regional proportionate removal of norepinephrine (NE) by neuronal uptake (Uptake $)_{1}$ ) in man. The measurement is based on the steady-state arterial and venous concentrations of tritiated NE and tritiated isoproterenol (ISO) during simultaneous infusion of both. The validity of this technique depends on the removal of circulating NE, but not of ISO, by sympathetic nerve endings and on there being no other factor contributing to the net difference in the plasma disappearance of these catecholamines. To test these hypotheses, we compared the removal of NE in the arm with that of ISO in 14 people and the effects of pretreatment with the specific inhibitor of Uptake , $_{1}$ desipramine, in 8 people. In all the subjects a greater percent of NE than of ISO was removed during passage of blood through the forearm (54 vs. $46 \%, P<0.0001$ ). Pretreatment with desipramine decreased significantly the removal of NE to virtually exactly that of ISO. The difference in NE and ISO clearances by arm tissues was therefore completely accounted

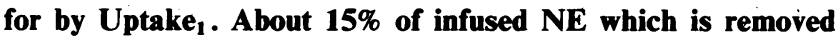

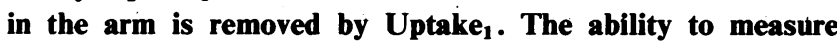
regional Uptake 1 should contribute to better understanding of the relationship between circulating levels of plasma NE and sympathetic neural activity and may allow detection of abnormalities of neuronal norepinephrine removal in clinical disease states.
\end{abstract}

\section{Introduction}

Many recent clinical studies have used venous plasma concentrations of norepinephrine (NE), ${ }^{1}$ the neurotransmitter of the sympathetic nervous system, as an index of overall sympathetic neural "tone" (1). Although antecubital venous levels of plasma NE agree well with directly recorded sympathetic activity (2, 3 ), the use of antecubital venous NE to measure average sympathetic outflow is probably too indirect to be completely valid, because several removal mechanisms intervene between the synaptic site of action of NE and the general circulation, because sympathetic outflow can be heterogeneous, and because

Address correspondence to Dr. Goldstein, Building $108 \mathrm{C} 118$, National Heart, Lung, and Blood Institute, National Institutes of Health, Bethesda, MD 20205.

Received for publication 9 October 1984 and in revised form 18 January 1985.

1. Abbreviations used in this paper: E, epinephrine; ISO, isoproterenol; NE, norepinephrine.

The Journal of Clinical Investigation, Inc.

Volume 76 , July $1985,15-21$ the sympathetic innervation of the arm itself contributes to the concentration of NE in antecubital venous blood (4).

The main removal mechanism for endogenously released $\mathrm{NE}$ is reuptake into the sympathetic nerve ending (Uptake ${ }_{1}$ ). In pithed rats, Uptake ${ }_{1}$ is responsible for about two-thirds of the concentration gradient for NE between vascular sympathetic neuroeffector junctions and the plasma (5). Because of the importance of neuronal removal of $\mathrm{NE}$ in determining the relationship between sympathetically mediated $N E$ release and plasma levels of $\mathrm{NE}$, attempts have been made to measure Uptake $_{1}$ activity in vivo. When tracer-labeled NE is infused intravenously to a steady-state and the infusion is then stopped, the concentration of radioactive $\mathrm{NE}$ in arm venous blood rapidly falls according to first-order disappearance kinetics for about $5 \mathrm{~min}$ and then falls more slowly thereafter. The rapid disappearance half-life $\left(t_{1 / 2}\right)$ is prolonged by desipramine, which

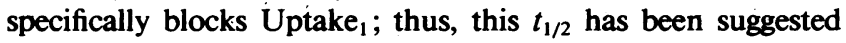
as a measure of neuronal NE removal (6). This technique is not entirely satisfactory. It requires blood sampling when radioactive $\mathrm{NE}$ is declining at an extremely rapid rate, so that errors of measurement can be large, and a rapid disappearance phase persists even after desipramine pretreatment.

Another technique has exploited the fact that the synthetic catecholamine, isoproterenol (ISO), is not a substrate for Uptake $_{1}$ (7). After stopping a simultaneous infusion of tracerlabeled NE and ISO, the ratio of radioactivity in ISO to that in NE increases rapidly, and the increase in this ratio is abolished by desipramine (8). The rate of increase in the ISO: $\mathrm{NE}$ ratio is independent of dilution and therefore has been suggested as a measure of Uptake ${ }_{1}(8)$ :

Neither of these techniques for measuring Uptake ${ }_{1}$ activity can be used to measure neuronal $\mathrm{NE}$ removal in a given vascular bed, and so neither can identify anatomic sites where Uptake $_{1}$ may be abnormal. Because of the nonufiformity of sympathetic outflow to the various vascular beds and the contribution of the arm to the overall clearance of infused $\mathrm{NE}$ from venous plasma, the estimation of total body Uptake activity by these techniques is subjềct to the same criticisms as the estimation of average sympathetic tone using antecubital venous concentrations of plasma NE. Accordingly, we wished to devise and validate a procedure to measure regional neuronal $\mathrm{NE}$ removal.

The procedure that we tested compared the removal of tritiated NE with the removal of tritiated ISO in the arm during simultaneous infusion of these catecholamines to a steady-state, with simultaneous sampling of brachial arterial and antecubital venous blood. We reasoned that, to the extent that infused $\mathrm{NE}$ is removed by neuronal uptake, a larger percent of tracer-labeled NE should be removed in the arm than of tracer-labeled ISO. Using this difference to measure Uptake $_{1}$ requires that there be no other factor contributing to 
the net difference in removal of these catecholamines. To test this hypothesis, we determined whether any observed difference in removal of NE and ISO in the arm is abolished in subjects

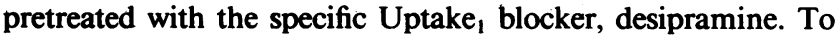
determine whether sympathetic neuronal removal of NE in the arm is stereospecific, we compared the Uptake $_{1}$ activity calculated using the tritium in l-NE and ISO with the activity calculated using the ${ }^{14} \mathrm{C}$-content in $d$-NE and the tritium in ISO when the infusate contained all three tracer-labeled catecholamines.

\section{Methods}

Subjects. The subjects were 16 people, including 12 healthy normotensive volunteers and 4 patients with essential hypertension. The mean age of the group was 31 yrs old (range, 19 to 58). Each subject had an unremarkable medical history (except for hypertension in those with the disease), physical examination, complete blood count, automated serum chemistry profile, and urinalysis. Hypertension was diagnosed on the basis of at least five outpatient visits where the systolic pressure averaged more than $140 \mathrm{mmHg}$ or the diastolic pressure averaged more than $90 \mathrm{mmHg}$. Patients with a diastolic blood pressure exceeding $115 \mathrm{mmHg}$ off medication, with end-organ damage or with a secondary form of hypertension, were excluded. The subjects were off all medications for at least 2 wk before the study.

Testing conditions. The subject reported to a patient observation room after having refrained from caffeinated foodstuffs, decaffeinated coffee, alcohol, and cigarette smoking for at least $18 \mathrm{~h}$. No other dietary restriction was imposed: Most of the testing sessions occurred in the morning, after a light breakfast. In subjects undergoing repeat testing, the studies occurred at the same time of day.

Testing procedure. With the subject supine, a plastic catheter was inserted percutaneously into the brachial artery after local infiltration of the overlying skin using $1 \%$ lidocaine. A catheter or needle was placed in each antecubital vein, one for drawing blood samples and the other for the infusion. After at least 20 min supine, a 5- or 10-ml blood sample was drawn from the arterial and venous sampling sites, and then the infusion began.

The infusate contained $50 \mu \mathrm{Ci}$ of tritiated $\mathrm{l}-\mathrm{NE}$ of high specific activity ( $>5 \mathrm{Ci} / \mathrm{mmol}$; New England Nuclear, Boston, $\mathrm{MA}$ ), $50 \mu \mathrm{Ci}$ of tritiated $d, l$-isoproterenol of high specific activity $(11.2 \mathrm{Ci} / \mathrm{mmol}$, New England Nuclear), and $10 \mu \mathrm{Ci}$ of $d-\left[{ }^{14} \mathrm{C}\right]$ norepinephrine $(33 \mathrm{mCi} /$ mmol, Amersham, Boston, MA). These radioactive drugs were diluted in 5\% dextrose in water to attain a total infusate volume of $65 \mathrm{ml}$. Of this, $60 \mathrm{ml}$ was infused intravenously over $20 \mathrm{~min}$ using an IMED controlled infusion pump (IMED Corp., San Diego, CA). Thus, the net tritiated $l$-NE infusion rate was $\sim 78 \mathrm{ng} / \mathrm{min}$, the tritiated $d, l$-ISO rate was $\sim 43 \mathrm{ng} / \mathrm{min}$, and the $d-\left[{ }^{14} \mathrm{C}\right] \mathrm{NE}$ rate was $\sim 2.4 \mu \mathrm{g} / \mathrm{min}$. No change in arterial or venous plasma total NE occurred due to infused tritiated $l \mathrm{NE}$ (the calculated increment in plasma NE was $\sim 3 \mathrm{pg} / \mathrm{ml}$ ), and no ISO was detectable in plasma due to infused tritiated $d, l$-ISO. Infusion of $d-\left[{ }^{14} \mathrm{C}\right] \mathrm{NE}$ caused venous plasma levels of total NE to increase by a few hundred picograms per milliliter, but $d$-NE is physiologically inactive. As a result, no changes in blood pressure or pulse rate occurred during any infusion.

Approximately $5 \mathrm{ml}$ of blood was sampled simultaneously from the artery and vein at $15 \mathrm{~min}$ after the start of the infusion, at $20 \mathrm{~min}$ (exactly when the infusion ended), and at 21, 22, 23, 24, 25, 40, and $80 \mathrm{~min}$ in 11 subjects. Most of the samples were obtained in $<20 \mathrm{~s}$. To ensure that steady-state conditions were approached by $20 \mathrm{~min}$, the infusate was diluted to $130 \mathrm{ml}$ and the infusion extended to 40 min for seven infusions in five subjects (three subjects underwent infusions both with and without pretreatment with desipramine), with sampling at 15, 20,30, and 40 min (exactly when the infusion ended) and then at $41,42,43,44$, and $45 \mathrm{~min} . d-\left[{ }^{14} \mathrm{C}\right] \mathrm{NE}$ was omitted in five subjects.

Catecholamine determinations. Blood for catecholamine determi- nations was drawn directly into chilled, evacuated, heparinized, glass tubes. After refrigerated centrifugation, the plasma was transferred to plastic storage tubes which were placed in dry ice until the plasma froze, and the tubes were then stored at $-70^{\circ} \mathrm{C}$ until the time of assay within 1 wk.

The catecholamine content of the plasma was assayed for each sample using liquid chromatography with electrochemical detection after a batch alumina extraction. This procedure was previously validated in this laboratory (9) and was modified for the purposes of the experimental design used in this study (8). The procedure allowed complete separation of the radioactivity in the chromatographic peak for NE from the radioactivity in the chromatographic peak for ISO. Unlabeled ISO was added to each plasma sample as both an internal standard and to ensure correct timing of the collection of the ISO peak. Effluent from the detector outlet was collected into glass scintillation vials when the NE and ISO peaks occurred; $10 \mathrm{ml}$ counting fluid was added to each vial; and the tritium and ${ }^{14} \mathrm{C}$-content of each vial was assayed by counting for $100 \mathrm{~min}$ in a liquid scintillation counter. The obtained raw counts per min were adjusted for background counts in the base-line plasma samples, for crossover from the ${ }^{14} \mathrm{C}$ to the tritium channel (when $d-\left[{ }^{14} \mathrm{C}\right] \mathrm{NE}$ was infused), for recovery of the internal standards through the alumina extraction, and for the volume of plasma used for assay. This liquid chromatographic-electrochemical procedure was used successfully to separate completely and to quantify the plasma levels of tritiated $l-\mathrm{NE}, d-\left[{ }^{14} \mathrm{C}\right] \mathrm{NE}$, and tritiated ISO.

Desipramine. In six subjects, the infusion was repeated after an interval of $1 \mathrm{wk} .3 \mathrm{~h}$ before this second infusion, the subjects took 125 $\mathrm{mg}$ desipramine by mouth. This was a dose that we previously found to abolish completely the increase in the ISO:NE ratio after stopping the infusion (8). Two other subjects were pretreated with desipramine before their only infusion.

Data analysis. Statistical testing included independent- and dependent-means $t$ tests and calculation of Pearson correlation coefficients (10). A $P$ value $<0.05$ defined statistical significance. Mean values were expressed $\pm 1 \mathrm{SD}$.

\section{Results}

The results for the 4 patients with hypertension were similar in all respects to those for the 12 normotensive subjects, and so the data were pooled.

Norepinephrine. Table I shows the tritium content of $l$-NE at the various times during and after the 20 -min infusion in 11 subjects. Steady-state conditions were approached by about $15 \mathrm{~min}$ (Table II). In all 11 subjects, as well as in all 3 subjects who received 40 -min infusions without desipramine pretreatment, the steady-state (15 and $20 \mathrm{~min}$ ) values for arterial tritiated NE were greater than for simultaneously obtained venous NE $(t=10.24, P<0.0001$ at $15 \mathrm{~min}$, and $t=9.71$, $P<0.0001$ at $20 \mathrm{~min}$ in 14 subjects). $54 \%( \pm 8.8 \%)$ of brachial arterial $l-\left[{ }^{3} \mathrm{H}\right] \mathrm{NE}$ was removed by the arm. The removal of $l$ $\left[{ }^{3} \mathrm{H}\right] \mathrm{NE}$ was the same as the removal of $d-\left[{ }^{14} \mathrm{C}\right] \mathrm{NE}(51.8 \pm 8.2 \%$ vs. $50.6 \pm 6.7 \%$ in 11 subjects).

In the first minute after the infusion ended, the tritiumand ${ }^{14} \mathrm{C}$-contents of arterial NE decreased by about two-thirds and in the first 2 min by over four-fifths (Fig. 1 and Table I). Thereafter, the radioactivity in arterial NE decreased as for a first-order process through the 25 -min sample $(5 \mathrm{~min}$ after the infusion ended). In contrast, the radioactivity in venous blood decreased by first-order kinetics as soon as the infusion ended. During the infusion, arterial levels of NE were higher than venous levels, but after $1 \mathrm{~min}$ following cessation of the infusion, venous levels exceeded arterial. For the time interval from 22 through $25 \mathrm{~min}$ (2-5 min after stopping the infusion), the tritium contents of arterial and venous NE decreased at 
Table I. Plasma Levels of $l-\left[{ }^{3} \mathrm{H}\right] N E, d, l-\left[{ }^{3} \mathrm{H}\right] I S O$, and $d-\left[{ }^{14} \mathrm{C}\right] N E$ during and after Their Simultaneous Intravenous Infusion

\begin{tabular}{|c|c|c|c|c|c|c|}
\hline Time & Arterial $\left.l-l^{3} \mathrm{H}\right] \mathrm{NE}$ & Venous $l-\left[{ }^{3} \mathrm{H}\right] \mathrm{NE}$ & Arterial $\left[{ }^{3} \mathrm{H}\right] \mathrm{ISO}$ & Venous $\left[{ }^{3} \mathrm{H}\right] \mathrm{ISO}$ & Arterial $d-\left[{ }^{14} \mathrm{C}\right] \mathrm{NE}$ & Venous $d-\left[{ }^{14} \mathrm{C}\right] \mathrm{NE}$ \\
\hline \multicolumn{7}{|l|}{$\min$} \\
\hline 15 & $426 \pm 109$ & $200 \pm 60$ & $432 \pm 118$ & $233 \pm 70$ & $120 \pm 30$ & $60 \pm 22$ \\
\hline 20 & $440 \pm 144$ & $219 \pm 103$ & $472 \pm 192$ & $265 \pm 123$ & $129 \pm 39$ & $64 \pm 27$ \\
\hline 21 & $148 \pm 45$ & $157 \pm 67$ & $188 \pm 67$ & $218 \pm 87$ & $45 \pm 17$ & $52 \pm 19$ \\
\hline 22 & $85 \pm 31$ & $123 \pm 53$ & $134 \pm 52$ & $164 \pm 70$ & $25 \pm 10$ & $36 \pm 16$ \\
\hline 23 & $51 \pm 26$ & $71 \pm 35$ & $91 \pm 46$ & $113 \pm 57$ & $16 \pm 8$ & $21 \pm 10$ \\
\hline 24 & $37 \pm 16$ & $51 \pm 24$ & $77 \pm 36$ & $92 \pm 44$ & $12 \pm 6$ & $16 \pm 8$ \\
\hline 25 & $29 \pm 14$ & $42 \pm 23$ & $67 \pm 33$ & $84 \pm 42$ & $9 \pm 5$ & $14 \pm 7$ \\
\hline 40 & $8 \pm 7$ & $11 \pm 11$ & $15 \pm 16$ & $18 \pm 17$ & $3 \pm 2$ & $4 \pm 3$ \\
\hline 80 & $8 \pm 13$ & $8 \pm 3$ & $5 \pm 3$ & $4 \pm 6$ & $2 \pm 2$ & $2 \pm 2$ \\
\hline
\end{tabular}

A solution containing $l-\left[{ }^{3} \mathrm{H}\right] \mathrm{NE},\left[{ }^{3} \mathrm{H}\right] \mathrm{SSO}$, and $d-\left[{ }^{14} \mathrm{C}\right] \mathrm{NE}$ was infused at a constant rate for $20 \mathrm{~min}$ in 11 subjects (see Methods). Results are expressed in cpm per milliliter and are mean values $\pm 1 \mathrm{SD}$.

the same rate $\left(t_{1 / 2}=1.75 \mathrm{~min}\right.$ for arterial, $t_{1 / 2}=1.72 \mathrm{~min}$ for venous).

ISO. Table I also shows the tritium content of ISO at the various times during and after the 20 -min infusion. As with $\mathrm{NE}$, the steady-state (15 and $20 \mathrm{~min}$ ) values for arterial ISO were greater than for simultaneously obtained venous ISO in all subjects $(t=9.60, P<0.0001$ at $15 \mathrm{~min}$, and $t=6.27, P$ $<0.001$ at $20 \mathrm{~min}$ in 14 subjects). As indicated in Fig. 1, the magnitude of the arteriovenous difference in radioactivity was less for ISO than for NE. This was true for all subjects at all time points. The mean removal of ISO in the arm was $45.6 \pm 8.1 \%$ among 14 subjects, significantly less than the removal of NE $(t=8.06, P<0.0001)$.

After the infusion, the tritium in ISO disappeared rapidly from arterial and venous blood but at a rate slower than that for NE (Fig. 1). As with NE, the arterial tritium content of ISO fell dramatically during the first minute after the infusion ended, and subsequently, arterial and venous tritium in ISO decreased in approximately parallel fashion $\left(t_{1 / 2}=2.70 \mathrm{~min}\right.$ arterial, $t_{1 / 2}=2.80 \mathrm{~min}$ venous blood for the time interval from 22 through $25 \mathrm{~min}$ ). The early $t_{1 / 2}$ for ISO was therefore about $60 \%$ longer than that for NE.

Because the arterial tritium contents of NE and of ISO at the steady-state exceeded by far the venous tritium contents of NE and of ISO, the clearance values for NE and ISO based on arterial radioactivity content were much lower than the clearance values based on venous radioactivity content $(6.0 \pm 1.4$ vs. $2.8 \pm 0.5 \mathrm{liter} / \mathrm{min}, t=9.72, P<0.0001$ ).

Table II. Net Tritium Content ${ }^{*}$ in NE and in ISO during Simultaneous Infusion of Both

\begin{tabular}{|c|c|c|c|c|}
\hline & \multicolumn{4}{|l|}{ Time (min) } \\
\hline & 15 & 20 & 30 & 40 \\
\hline Arterial NE & $566 \pm 191$ & $562 \pm 172$ & $575 \pm 154$ & $563 \pm 136$ \\
\hline Venous NE & $248 \pm 107$ & $256 \pm 82$ & $246 \pm 76$ & $256 \pm 90$ \\
\hline Arterial ISO & $313 \pm 53$ & $313 \pm 64$ & $329 \pm 54$ & $326 \pm 61$ \\
\hline Venous ISO & $134 \pm 22$ & $152 \pm 38$ & $159 \pm 43$ & $161 \pm 37$ \\
\hline
\end{tabular}

*Net tritium content given in cpm per milliliter.

$\mathrm{NE}$ and ISO were infused simultaneously for $40 \mathrm{~min}$. Values shown are for seven infusions in four subjects, three infusions without desipramine pretreatment and four with desipramine treatment. Means are expressed \pm 1 SD.
Proportionate regional removal of $N E$ by Uptake $_{1}$. The proportionate removal of $l-N E$ by Uptake $_{1}$ was calculated by subtracting the percent removal of ISO in the arm from the percent removal of $l-\left[{ }^{3} \mathrm{H}\right] N E$ and dividing by the percent removal of $l-\left[{ }^{3} \mathrm{H}\right] N E$ for each subject. Individual values are shown in Table III. About $15 \%$ of the NE which is removed in the arm is removed by Uptake . $_{\text {. }}$.

Desipramine. The results shown in Table IV and in Fig. 2 demonstrate that pretreatment with desipramine profoundly affected the pharmacokinetics of infused NE with virtually no effect on the pharmacokinetics of infused ISO. Desipramine significantly increased the steady-state concentrations of tritium in NE in arterial and especially in venous blood $(t=3.10, P$ $<0.05$, and $t=4.14, P<0.01$, Table IV), but had no effect on either arterial or venous steady-state concentrations of tritiated ISO (Table IV). Because of these effects on the steadystate radioactivity concentrations in $\mathrm{NE}$, desipramine pretreatment diminished the clearance of NE calculated from arterial and especially from venous blood in the six subjects who

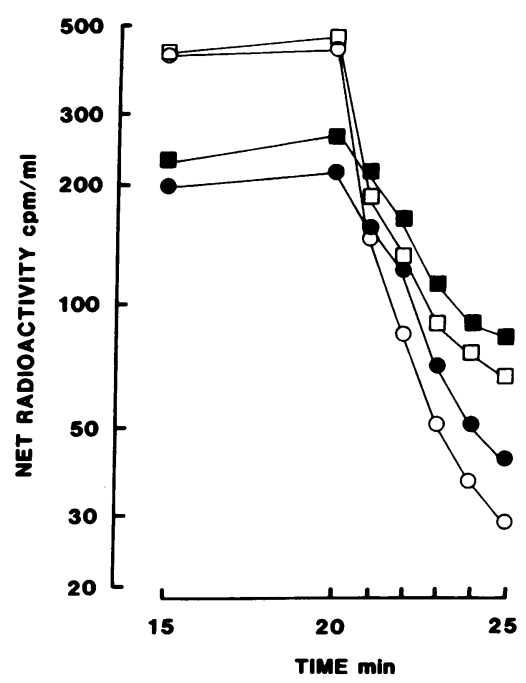

Figure 1. Plasma levels of $\left[{ }^{3} \mathrm{H}\right] \mathrm{NE}$ and $\left[{ }^{3} \mathrm{H}\right] \mathrm{ISO}$ during and after their simultaneous infusion. Each point shows the mean values for 11 subjects who underwent a 20 -min infusion. $O$, arterial NE; •, venous NE; $\square$, arterial ISO; $\bullet$, venous ISO. 
Table III. Individual Values for Steady-state Tritium Content in Plasma NE and ISO,

Percent Removal of NE and ISO in the Arm, and Percent Removal of NE by Uptake

\begin{tabular}{|c|c|c|c|c|c|c|}
\hline Subject & & Steady-state $\left[{ }^{3} \mathrm{H}\right] \mathrm{NE}$ & Steady-state $\left[{ }^{3} \mathrm{H}\right] \mathrm{ISO}$ & \% NE removal & \% ISO removal & \% Uptake \\
\hline \multirow[t]{2}{*}{1} & A & 264 & 256 & 43.6 & 37.9 & 13.8 \\
\hline & $\mathbf{V}$ & 149 & 159 & & & \\
\hline \multirow[t]{2}{*}{2} & A & 522 & 518 & 42.5 & 40.5 & 4.7 \\
\hline & $\mathbf{V}$ & 300 & 308 & & & \\
\hline \multirow[t]{2}{*}{3} & $\mathbf{A}$ & 698 & 670 & 41.9 & 36.4 & 13.1 \\
\hline & $\mathbf{V}$ & 405 & 426 & & & \\
\hline \multirow[t]{2}{*}{4} & A & 374 & 392 & 54.0 & 50.0 & 7.4 \\
\hline & $\mathbf{V}$ & 172 & 196 & & & \\
\hline \multirow[t]{2}{*}{5} & A & 431 & 541 & 49.2 & 41.8 & 15.0 \\
\hline & $\mathbf{V}$ & 219 & 315 & & & \\
\hline \multirow[t]{2}{*}{6} & A & 389 & 458 & 46.3 & 33.4 & 27.8 \\
\hline & $\mathbf{V}$ & 209 & 305 & & & \\
\hline \multirow[t]{2}{*}{7} & $\mathbf{A}$ & 509 & 674 & 58.2 & 52.2 & 9.9 \\
\hline & $\mathbf{V}$ & 213 & 322 & & & \\
\hline \multirow[t]{2}{*}{8} & $\mathbf{A}$ & 467 & 485 & 69.4 & 60.8 & 12.4 \\
\hline & V & 143 & 190 & & & \\
\hline \multirow[t]{2}{*}{9} & $\mathbf{A}$ & 356 & 383 & 53.1 & 44.9 & 15.4 \\
\hline & $\mathbf{V}$ & 167 & 211 & & & \\
\hline \multirow[t]{2}{*}{10} & $\mathbf{A}$ & 467 & 393 & 57.5 & 46.8 & 18.6 \\
\hline & $\mathbf{V}$ & 194 & 209 & & & \\
\hline \multirow[t]{2}{*}{11} & $\mathbf{A}$ & 296 & 199 & 55.7 & 50.3 & 9.7 \\
\hline & $\mathbf{v}$ & 131 & 99 & & & \\
\hline \multirow[t]{2}{*}{12} & $\mathbf{A}$ & 424 & 261 & 54.2 & 42.1 & 22.3 \\
\hline & $\mathbf{v}$ & 194 & 151 & & & \\
\hline \multirow[t]{2}{*}{13} & $\mathbf{A}$ & 624 & 382 & 64.3 & 55.8 & 13.2 \\
\hline & $\mathbf{v}$ & 223 & 169 & & & \\
\hline \multirow[t]{2}{*}{14} & A & 552 & 324 & 69.4 & 56.8 & 18.2 \\
\hline & $\mathbf{v}$ & 169 & 140 & & & \\
\hline \multirow[t]{2}{*}{ Mean } & A & $455 \pm 120^{*}$ & $424 \pm 144^{*}$ & $54.2 \pm 9.1$ & $46.4 \pm 8.3$ & $14.3 \pm 6.0$ \\
\hline & V & $206 \pm 71$ & $229 \pm 92$ & & & \\
\hline
\end{tabular}

First row for each subject shows values for arterial and second row values for venous blood. Steady-state values are the mean of values at 15 , 20,30 , and $40 \mathrm{~min}$. Units of steady-state tritium content are $\mathrm{cpm}$ per milliliter. \% Uptake ${ }_{1}=[(\% \mathrm{NE}$ removal $-\%$ ISO removal $) /(\% \mathrm{NE}$ removal)] $\times 100$. * Arterial-venous difference significant with $P<0.001$.

underwent two infusions $(6.3 \pm 1.1$ to $4.2 \pm 1.7 \mathrm{liter} / \mathrm{min}$ venous, $t=4.15, P<0.01 ; 2.6 \pm 0.3$ to $2.1 \pm 0.4 \mathrm{liter} / \mathrm{min}$ arterial, $t$ $=2.59, P<0.05$ ). As indicated in Fig. 2, desipramine prolonged the $t_{1 / 2}$ for NE plasma disappearance in the time interval from 2 through $5 \mathrm{~min}$ after the infusion ended, with the resultant value, $2.91 \mathrm{~min}(n=7$ subjects, arterial blood), similar to the $t_{1 / 2}$ for ISO plasma disappearance in this time interval.

Pretreatment with desipramine did not significantly affect base-line concentrations of NE in arterial $(190 \pm 104 \mathrm{pg} / \mathrm{ml}$ without, and $130 \pm 58 \mathrm{pg} / \mathrm{ml}$ with desipramine pretreatment) or venous blood $(210 \pm 101 \mathrm{pg} / \mathrm{ml}$ without, and $208 \pm 88 \mathrm{pg} / \mathrm{ml}$ with desipramine pretreatment). Pretreatment with desipramine also did not affect arterial or venous base-line concentrations of epinephrine. However, it did increase the arteriovenous increment in $\mathrm{NE}$ from $21 \pm 44 \mathrm{pg} / \mathrm{ml}$ (12 subjects) to $77 \pm 46$ $\mathrm{pg} / \mathrm{ml}$ (8 subjects) $(t=2.80, P<0.05)$.

Among seven patients with detectable arterial and venous base-line plasma epinephrine $(E)$, the correlation between the percent removal of $\mathrm{E}$ and the percent removal of $\mathrm{NE}$ was $\mathbf{0 . 6 7}$ $(P<0.05)$. However, in two other subjects, the resting arterial levels of $\mathrm{E}$ were $<10 \mathrm{pg} / \mathrm{ml}$ and the venous levels were undetectable, and in two others, neither arterial nor venous $E$ levels were detectable.

In the six subjects who underwent two infusions, one without and one with pretreatment with desipramine, the percent removal of $\mathrm{NE}$ in the arm was $58.6 \pm 6.7 \%$ without desipramine and $48.3 \pm 10.0 \%$ with desipramine. The percent 


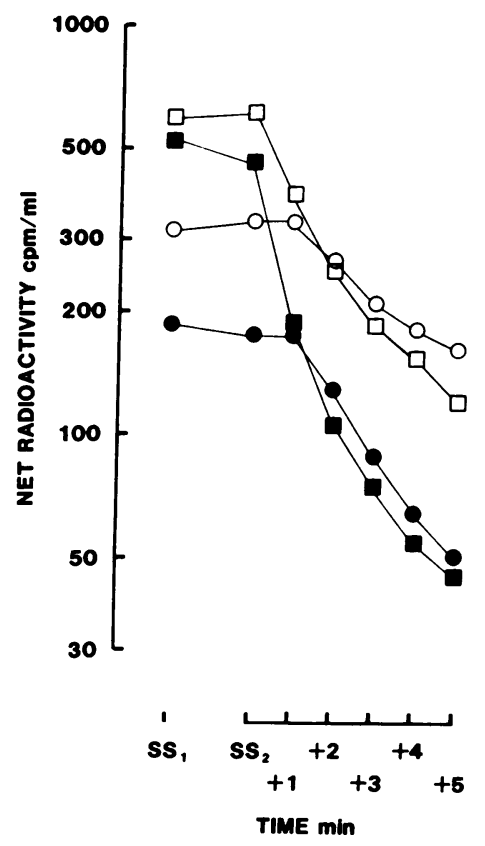

Figure 2. Plasma levels of $\left[{ }^{3} \mathrm{H}\right] \mathrm{NE}$ during and after its infusion, with and without pretreatment with $125 \mathrm{mg}$ oral desipramine. Each point shows the mean for six subjects who underwent both infusions. $O$, venous NE pretreated with desipramine; •, venous NE, no pretreatment; $\square$, arterial NE pretreated with desipramine; $\mathbf{a}$, arterial NE, no pretreatment. Since subjects underwent either 20 - or 40 min infusions, values for the last two steady-state (SS) samples (15 and 20 min or else 30 and $40 \mathrm{~min}$ ) are shown. Values for 40 min were adjusted for dilution of the infusate.

removal of ISO in the arm was $49.5 \pm 7.6 \%$ without desipramine and $49.8 \pm 8.0 \%$ with desipramine. Therefore, blockade of Uptake $_{1}$ with desipramine completely abolished the difference between the removal of NE and the removal of ISO in the arm.

The effects of desipramine on $d-\left[{ }^{14} \mathrm{C}\right] \mathrm{NE}$ pharmacokinetics were similar to its effects on $l-\left[{ }^{3} \mathrm{H}\right] \mathrm{NE}$. In all three subjects who received $d-\left[{ }^{14} \mathrm{C}\right] \mathrm{NE}$ in two infusions, desipramine increased the steady-state arterial and venous concentrations of $d-\left[{ }^{14} \mathrm{C}\right] \mathrm{NE}$ (mean increase: $37 \%$ arterial, $94 \%$ venous) and decreased the percent of $d-\left[{ }^{14} \mathrm{C}\right] \mathrm{NE}$ removed in the arm from 58 to $40 \%$, the latter value similar to that for ISO $(42 \%)$.

\section{Discussion}

The present report introduces a method to measure the regional proportionate removal of NE by Uptake $e_{1}$. Regional Uptake $_{1}$ activity can be calculated from the steady-state arterial and venous concentrations of tritium in NE and in ISO during simultaneous infusion of both tracer-labeled catecholamines,

assuming that ISO is not a substrate for Uptake $_{1}$, that a significant proportion of arterial NE reaches Uptake ${ }_{1}$ sites, and that Uptake $_{1}$ is the only process responsible for the net difference in removal of NE and ISO. The validity of these assumptions is supported by previous observations as well as the results of the present study.

Lack of Uptake, of ISO. Hertting (7) was the first to demonstrate that, in contrast with NE, ISO is not a substrate for neuronal uptake in the rat heart. Callingham and Burgen (11) and Bonisch (12) confirmed this finding. Using the isolated nictitating membrane of the cat as an organ innervated exclusively by sympathetic adrenergic fibers, Draskoczy and Trendelenburg (13) showed that denervation of the smooth muscle in the membrane produced a marked decrease in accumulation of tritiated NE but had no effect on the accumulation of tritiated ISO. ISO has such a low removal rate into nerve endings that it has been used as a model substance for studies of extraneuronal uptake of catecholamines.

Uptake $_{1}$ of circulating $N E$. Several results of the present study support the view that a proportion of circulating NE is removed by Uptake $_{1}$. Pretreatment with desipramine, a specific blocker of Uptake ${ }_{1}$, increased the steady-state concentrations of tritiated NE in arterial and arm venous blood, prolonged the early $t_{1 / 2}$ of plasma disappearance of NE, and decreased the percent of arterial NE removed in the arm to exactly the percent of ISO removed in the arm. Esler et al. (6) and Goldstein et al. (7) have also found that blockade of Uptake increases steady-state concentrations of tritiated NE in venous blood, indicating decreased total body clearance of NE, and prolongs the early $t_{1 / 2}$ of plasma disappearance of NE. Using a pithed, adrenal-demedullated, vagotomized, alpha-2-adrenoceptor blocked rat model, Kopin et al. (5) have shown that

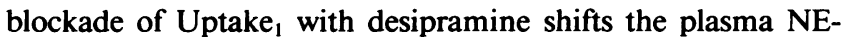
pressor response relationship to the left during intravenous $\mathrm{NE}$ injection; this indicates that, for a given amount of circulating NE, blockade of neuronal NE removal causes a greater amount of occupation of postsynaptic adrenoceptors. Desipramine treatment caused the estimated synaptic cleftplasma concentration gradient for NE to decrease by about two-thirds for both NE infusion and, in the reverse direction, for sympathetic stimulation, leading the investigators to suggest that removal of both released and infused NE is mainly by neuronal uptake in this model.

In all these studies, as well as the present one, it has been

Table IV. Effect of Pretreatment with Desipramine on the Steady-state Levels of Plasma $\left[{ }^{3} \mathrm{H}\right] \mathrm{NE}$ and $\left[{ }^{3} \mathrm{H}\right] \mathrm{ISO}$

\begin{tabular}{|c|c|c|c|c|c|c|c|c|}
\hline Subject & $\begin{array}{l}\text { Control } \\
\mathrm{NE}_{\text {. }}\end{array}$ & Desip NE & $\begin{array}{l}\text { Control } \\
\mathrm{NE}_{\mathrm{v}}\end{array}$ & Desip NE & $\begin{array}{l}\text { Control } \\
\text { ISO. }\end{array}$ & Desip ISO. & $\begin{array}{l}\text { Control } \\
\text { ISO }_{\mathbf{v}}\end{array}$ & Desip ISO \\
\hline 8 & 404 & 647 & 138 & 398 & 441 & 509 & 193 & 308 \\
\hline 9 & 355 & 533 & 167 & 299 & 377 & 340 & 217 & 167 \\
\hline 10 & 435 & 478 & 166 & 288 & 381 & 238 & 168 & 137 \\
\hline 12 & 425 & 781 & 208 & 344 & 265 & 352 & 162 & 164 \\
\hline 13 & 544 & 755 & 249 & 398 & 352 & 400 & 181 & 197 \\
\hline 14 & 567 & 571 & 195 & 205 & 332 & 210 & 149 & 80 \\
\hline Mean & $455 \pm 83$ & $628 \pm 122^{*}$ & $187 \pm 39$ & $322 \pm 74 \ddagger$ & $358 \pm 59$ & $342 \pm 109$ & $178 \pm 24$ & $175 \pm 76$ \\
\hline
\end{tabular}

Desip, pretreated with $125 \mathrm{mg}$ oral desipramine $3 \mathrm{~h}$ before the infusion; $\mathrm{ISO}_{\mathrm{a}}$, arterial ISO; $\mathrm{ISO}_{\mathrm{v}}$, venous ISO; $\mathrm{NE}_{\mathrm{a}}$, arterial NE; NE , venous NE. Units of tritium are cpm per milliliter. All values are for the 20 -min blood samples. * Significant difference from control infusion, $P<0.05$. $\ddagger$ Significant difference from control infusion, $P<0.01$. 
presumed that the predominant if not exclusive pharmacologic

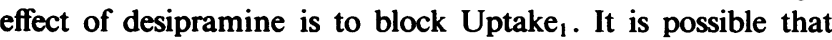
other effects occur, but none has definitively been established.

Similarity of extraneuronal removal of $N E$ and ISO. In the present study, in all the subjects tested, a larger percent of NE than of ISO was removed during passage of blood through the arm. Since ISO is not a substrate for Uptake ${ }_{1}$, this difference provides a measure of Uptake ${ }_{1}$, if no other net difference occurs in the regional removal of NE and ISO. For instance, if ISO were removed to a greater extent than NE at extraneuronal uptake sites, then the calculated proportionate removal of NE by Uptake ${ }_{1}$, based on the difference in NE and ISO removals, would be an underestimate. We found, however, that after pretreatment with desipramine, the removal of NE in the arm decreased to exactly that of ISO. If extraneuronal removal of ISO differed from that for NE, then we would have expected that pretreatment with desipramine would result in a difference in the proportion of ISO and NE removed. Although we used only one dose of desipramine, it is unlikely

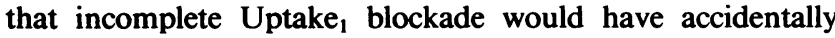
balanced the removals of NE and ISO, despite a difference in extraneuronal uptake of NE and ISO. Draskoczy and Trendelenburg (13) found that in the denervated cat nictitating membrane, tritiated ISO accumulated more rapidly than tritiated NE, indicating preferential extraneuronal uptake of ISO in this tissue. In contrast, in a study more closely analogous to ours, Gryglewski and Vane (14) compared the removal of $\mathrm{NE}$ and of ISO in several vascular beds in the dog using a blood-bathed organ technique, and they found that administration of phenoxybenzamine, which they used to inhibit neuronal uptake of NE, caused the removal of NE in the hindlimb to decrease from 61 to $33 \%$, whereas the removal of ISO was unchanged (34\% without phenoxybenzamine, $34 \%$ with phenoxybenzamine). In the dog hindlimb, then, no net difference in removal of NE and of ISO occurs other than due to neuronal uptake. Finally, in patients with idiopathic orthostatic hypotension, in whom degeneration of peripheral sympathetic nerve endings occurs without any known defect in extraneuronal NE removal, the plasma disappearance of ISO is about the same as the plasma disappearance of NE (15).

Arterial-venous differences in $N E$ kinetics. Our finding of much higher steady-state levels of tritiated NE in arterial than venous blood confirms the findings of Hilsted et al. (16) and Saar et al. (17). Use of venous plasma NE levels grossly overestimates total body clearances of NE. Since the lungs extract about one-fourth of NE in mixed venous blood (18), even use of arterial plasma would probably overestimate total body NE clearance.

Whereas the steady-state arterial concentration of tritiated $\mathrm{NE}$ exceeded the venous concentration of tritiated $\mathrm{NE}$, once the infusion was stopped the arterial level of tritiated NE fell. precipitously for 1 to $2 \mathrm{~min}$ and thereafter remained less than the venous level. This finding is similar to that reported by Saar et al. (17) and may be attributed to dilution of the central vascular compartment as follows. In studies of the central circulation, Newman et al. (19) showed that the central circulatory volumes behave as serial compartments from which dye is consecutively washed out in an exponential fashion. In the present study, after stopping the intravenous infusion of $l$ $\left[{ }^{3} \mathrm{H}\right] \mathrm{NE}$, the excess $\left[{ }^{3} \mathrm{H}\right] \mathrm{NE}$ in the central circulation which had been maintained by the infused labeled compound was similarly washed out. This excess would be expected to decline in an exponential fashion to a level determined by the $\left[{ }^{3} \mathrm{H}\right] \mathrm{NE}$ content of the venous blood. Thus, after stopping the infusion, the initial decrease in arterial $\left[{ }^{3} \mathrm{H}\right] \mathrm{NE}$ resulted from both this central circulatory dilution and the subsequent decline in venous $\left[{ }^{3} \mathrm{H}\right] \mathrm{NE}$. The time required for the washout phase would be expected to be similar to that for the appearance and passage of a dye injected into the antecubital vein and monitored at the brachial artery. Bousvaros et al. (20) found that, in the absence of flushing, the appearance time (13.4 s) and passage time (40.4 s) from the antecubital vein to the ear lobe was $54 \mathrm{~s}$. Therefore, ignoring recirculation, it would be expected that 1-2 $\mathrm{min}$ would be required to wash out the infused $\left[{ }^{3} \mathrm{H}\right] \mathrm{NE}$ remaining in the central compartment after cessation of the infusion. This washout accounts for a major portion of the rapid decline in arterial $\left[{ }^{3} \mathrm{H}\right] \mathrm{NE}$ levels during the first minute after stopping the infusion. After this time interval, arterial and venous $\left[{ }^{3} \mathrm{H}\right] \mathrm{NE}$ levels would be expected to decrease at the same rate, and this is what we observed.

Relation between Uptake, blockade and NE release. Pretreatment with desipramine to block Uptake $_{1}$ did not cause increases in either arterial or venous plasma NE, despite enhancement of the arteriovenous increment in plasma NE. Therefore, desipramine apparently can inhibit NE release. Consistent with this suggestion, Linnoila et al. (21) found reduced urinary excretion of $\mathrm{NE}$ and its major metabolites in depressed patients treated with desipramine, and Polinsky et al. (22) have recently found that patients with idiopathic orthostatic hypotension who have decreased NE spillover rates into plasma also have decreased Uptake ${ }_{1}$ activity. One way desipramine may inhibit sympathetically mediated NE release is by increasing the NE concentration in the region of the nerve terminals due to inhibition of reuptake. This would result in stimulation of presynaptic alpha-2-adrenoceptors and diminished release of NE. Alternatively, since Uptake blockade enhances pressor responses for a given amount of released NE, decreased sympathetic nerve traffic after desipramine may reflect reflexive sympathoinhibition by increased baroreceptor afferent activity.

Arteriovenous decrement of plasma $E$ to measure $N E$ removal. Unlike NE, which is released from sympathetic nerve endings in innervated beds throughout the body, $\mathrm{E}$ is derived almost exclusively from the adrenal medulla. Since both catecholamines are substrates for Uptake $_{1}$ as well as for extraneuronal removal, the arteriovenous decrement in plasma E may provide a measure of regional removal of NE (23). If this suggestion is correct, then the rate of sympathetically mediated NE release can be estimated from the arteriovenous increment in plasma $\mathrm{NE}$, the proportion of circulating $\mathrm{E}$ removed in the bed, and the blood flow to the bed. Brown et al. (23) found that in patients with pheochromocytoma, an adrenal tumor which secretes $\mathrm{NE}$ and $\mathrm{E}$, the percent removal of NE was about the same as the percent removal of $E$ in several organ beds. No study has directly determined whether, in fact, the percent removal of $E$ in a vascular bed validly measures the percent removal of NE. The results of the present study can be applied to this issue. Among seven patients, there was a significant correlation $(r=0.67)$ between the percent of $E$ removed in the arm and the percent of $N E$ removed. However, in two other subjects, the resting arterial level of $E$ 
was $<10 \mathrm{pg} / \mathrm{ml}$ and the venous level was undetectable, and in two others, neither arterial nor venous $E$ was detectable, despite a limit of detection of $\sim 5 \mathrm{pg} \mathrm{E} / \mathrm{ml}$. One cannot rely on arteriovenous differences in plasma $\mathrm{E}$ to measure regional NE removal in resting subjects.

Calculation of regional total and neuronal $N E$ removal. The present study involved measurement only of the proportion of regional NE removal due to Uptake ${ }_{1}$. The actual rate of neuronal NE uptake can be calculated only if the regional blood flow is known.

The present technique should lead to more valid interpretations than previously about the meaning of plasma NE as an indicator of sympathetic neural activity. The technique complements that of Esler and associates $(24,25)$ for measuring regional NE kinetics.

Because the present technique uses simultaneously obtained steady-state arterial and venous blood samples, combined assay of NE and ISO in the same chromatograph of the same blood sample with complete chromatographic separation of the NE and ISO peaks, and accurate measurement of the radioactivity in each chromatographic peak (by counting in a liquid scintillation spectrometer for $100 \mathrm{~min}$ ), we feel that it can validly be used to quantify regional removal of NE and ISO in order to

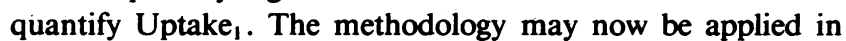
studies about the pathophysiology of several cardiovascular disorders in which altered regional sympathetic activity may occur.

\section{References}

1. Goldstein, D. S., R. McCarty, and I. J. Kopin. 1983. Relationship between plasma norepinephrine and sympathetic neural activity. Hypertension. 5:552-559.

2. Wallin, B. G., G. Sundlof, B.-M. Eriksson, P. Dominiak, H. Grobecker, and L. E. Lindblad. 1981. Plasma noradrenaline correlates to sympathetic muscle nerve activity in normotensive man. Acta Physiol. Scand. 111:69-73.

3. Morlin, C., B. G. Wallin, and B. M. Eriksson. 1983. Muscle sympathetic activity and plasma noradrenaline in normotensive and hypertensive man. Acta Physiol. Scand. 119:117-121.

4. Folkow, B., G. F. DiBona, P. Hjemdahl, P. H. Toren, and B. G. Wallin. 1983. Measurements of plasma norepinephrine concentrations in human primary hypertension. A word of caution on their applicability for assessing neurogenic contributions. Hypertension. 5: 399-403.

5. Kopin, I. J., Z. Zukowska-Grojec, M. Bayorh, and D. S. Goldstein. 1984. Estimation of intrasynaptic norepinephrine concentrations at vascular neuroeffector junctions in vivo. Naunyn-Schmiedeberg's Arch. Pharmacol. 325:298-305.

6. Esler, M., G. Jackman, P. Leonard, H. Skews, A. Bobik, and P. Korner. 1981. Effect of norepinephrine uptake blockers on norepinephrine kinetics. Clin. Pharmacol. Ther. 29:12-20.

7. Hertting G. 1964. The fate of ${ }^{3} \mathrm{H}$-isoproterenol in the rat. Biochem. Pharmacol. 13:1119-1128.

8. Goldstein, D. S., D. Horwitz, H. R. Keiser, R. J. Polinsky, and I. J. Kopin. 1983. Plasma $l\left[{ }^{3} \mathrm{H}\right]$ norepinephrine, $d-\left[{ }^{14} \mathrm{C}\right]$ norepinephrine, and $d, l-\left[{ }^{3} \mathrm{H}\right]$ isoproterenol kinetics in essential hypertension. J. Clin. Invest. 72:1748-1758.

9. Goldstein, D. S., G. Z. Feuerstein, J. L. Izzo, Jr., I. J. Kopin, and H. R. Keiser. 198i. Validity and reliability of liquid chromatography with electrochemical detection for measuring plasma levels of norepinephrine and epinephrine in man. Life Sci. 28:467-475.

10. Edwards, A. L. 1967. Statistical Methods. Holt, Rinehart, \& Winston, New York. 200-225.

11. Callingham, B. A., and A. S. V. Burgen. 1966. The uptake of isoprenaline and noradrenaline by the perfused rat heart. Mol. Pharmacol. 2:37-42.

12. Bonisch, H. 1978. Further studies on the extraneuronal uptake and metabolism of isoprenaline in the perfused rat heart. NaunynSchmiedeberg's Arch. Pharmacol. 303:121-131.

13. Draskoczy, P. R., and U. Trendelenburg. 1970. Intraneuronal and extraneuronal accumulation of sympathomimetic amines in the isolated nictitating membrane of the cat. J. Pharm. Exp. Ther. 174: 290-306.

14. Gryglewski, R., and J. R. Vane. 1970. The inactivation of noradrenaline and isoprenaline in dogs. Br. J. Pharmacol. 39:573-584.

15. Polinsky, R. J., D. S. Goldstein, D. Horwitz, H. R. Keiser, and I. J. Kopin. 1983. Plasma catecholamine kinetics in patients with chronic autonomic failure and control subjects. Proc. 5th Catecholamine Symp., Göteborg, Sweden. Pergamon, New York. 250 pp.

16. Hilsted, J., N. J. Christensen, and S. Madsbad. 1983. Whole body clearance of norepinephrine. The significance of arterial sampling and of surgical stress. J. Clin. Invest. 71:500-505.

17. Saar, N., A. W. Bachman, R. V. Jackson, and R. D. Gordon. 1983. Different norepinephrine disappearance rate in venous and arterial plasma in man. Clin. Exper. Hyper. A5:31-40.

18. Sole, M. J., M. Drobac, L. Schwartz, M. N. Hussain, and E. F. Vaughan-Neil. 1979. The extraction of circulating catecholamines by the lungs in normal man and in patients with pulmonary hypertension. Circulation. 60:160-163.

19. Newman, E. V., M. Merrell, A. Genecin, C. Monge, W. R. Milnor, and W. P. McKeever. 1951. The dye dilution method for describing the central circulation. Circulation. 4:735-746.

20. Bousvaros, G. A., W. H. Palmer, P. Sekelj, and M. McGregor. 1963. Comparison of central and peripheral injection sites in the estimation of cardiac output by dye dilution curves. Circulation. 12: 317-321.

21. Linnoila, M., F. Karoum, H. M. Calil, I. J. Kopin, and W. Z. Potter. 1982. Alteration of norepinephrine metabolism with desipramine and zimelidine in depressed patients. Arch. Gen. Psychiatry 39:10251028.

22. Polinsky, R. J., D. S. Goldstein, R. T. Brown, H. R. Keiser, and I. J. Kopin: 1985. Decreased sympathetic neuronal uptake in idiopathic orthostatic hypotension. Ann. Neurol. In press.

23. Brown, M. J., D. A. Jenner, D. J. Allison, and C. T. Dollery. 1981. Variations in individual organ release of noradrenaline measured by an improved radioenzymatic technique: limitations of peripheral venous measurements in the assessment of sympathetic nervous activity. Clin. Sci. 61:585-590.

24. Esler, M., G. Jennings; P. Korner, P. Blombery, F. Burke, I. Willett, and P. Leonard. 1984. Total, and organ-specific, noradrenaline plasma kinetics in essential hypertension. Clin. Exper. Hypers. Part A Theory Pract. 6:507-521.

25. Blombery, P. A., and B. G. J. Heinzow. 1983. Cardiac and pulmonary norepinephrine release and removal in the dog. Circ. Res. 53:688-694. 